DEMINICIS, B.B. et al. Efeitos de diferentes aditivos sobre a composição bromatológica e pH de silagens de capim elefante. PUBVET, Londrina, V. 8, N. 13, Ed. 262, Art. 1739, Julho, 2014.

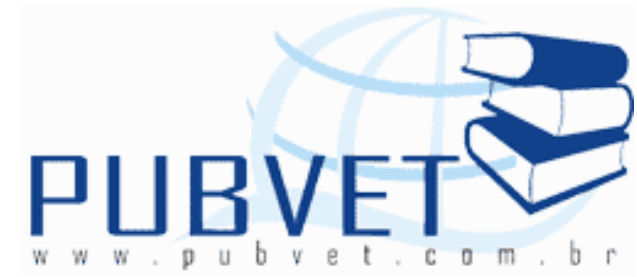

PUBVET, Publicações em Medicina Veterinária e Zootecnia.

\title{
Efeitos de diferentes aditivos sobre a composição bromatológica e pH de silagens de capim elefante
}

\begin{abstract}
Bruno Borges Deminicis ${ }^{1}$, Rafael Pavesi Araújo ${ }^{2}$, Norberto Silva Rocha ${ }^{3}$, Matheus Lima Corrêa Abreu², Rafaela Neves Guerra ${ }^{4}$, Vitor Luiz de Souza Hertel $^{5}$, Antônio Delunardo Pandolfi Filho ${ }^{4}$, Patricia do Rosário Rodrigues ${ }^{4}$, Isabela Moraes Amorim ${ }^{6}$
\end{abstract}

${ }^{1}$ Zootecnista, D.Sc. Prof.Dr. DZOO-CCA-UFES, brunodeminicis@hotmail.com

${ }^{2}$ Zootecnista, Doutorando em Produção Animal da UENF/CCTA/LZNA,

${ }^{3}$ Zootecnista, Pós-Doutorando em Zootecnia da UFVJM.

${ }^{4}$ Zootecnista, Mestranda em Ciências Veterinárias da UFES.

${ }^{5}$ Zootecnista.

${ }^{6}$ Graduanda em Zootecnia da UFES, Bolsista de IC - CNPq.

\section{Resumo}

Objetivou-se com este trabalho, verificar a eficiência de diferentes aditivos sobre a composição bromatológica e pH da silagem de capim-elefante. O plantio do capim-elefante cv. Napier (Pennisetum purpureum Schum.) foi feito em covas de $25 \mathrm{~cm}$ de profundidade com espaçamento entre linhas de $80 \mathrm{~cm}$, após o preparo do solo. O capim-elefante foi colhido aos 180 dias de idade e triturado em partículas de 0,5 a $2,0 \mathrm{~cm}$. Os tratamentos consistiram em Controle (sem aditivo); Fubá, à $8 \%$ da matéria natural; Cloreto de sódio, à $8 \%$ da matéria natural; Uréia, à $8 \%$ da matéria natural, Açúcar cristal, à $8 \%$ da matéria natural e Fubá mais açúcar cristal, onde Fubá a 4\% da matéria natural 
DEMINICIS, B.B. et al. Efeitos de diferentes aditivos sobre a composição bromatológica e pH de silagens de capim elefante. PUBVET, Londrina, V. 8, N. 13, Ed. 262, Art. 1739, Julho, 2014.

e Açúcar cristal a $4 \%$ da matéria natural (totalizando $8 \%$ ). As análises realizadas foram de matéria seca (MS), proteína bruta (PB), fibra em detergente neutro (FDN), fibra em detergente ácido (FDA), lignina (LIG), extrato etéreo (EE) e matéria mineral (MM). O Tratamento com cloreto de sódio (8\%) proporcionou a confecção da melhor silagem, levando em consideração $\mathrm{o}$ pH e composição bromatológica quando comparadas às silagens confeccionadas com os outros aditivos testados. Contudo a silagem com este aditivo não possui níveis adequados de proteína para uma dieta equilibrada baseada apenas em silagem. A uréia na dose utilizada (8\%) inviabiliza a silagem pelo alto poder de alcalinização. $O$ alto tempo de corte do capim elefante (180 dias) reduziu o valor bromatológico da silagem.

Palavras-chave: Silagem, Conservação de Forragem, Pennisetum purpureum

\title{
Effects of different additives on chemical composition and $\mathrm{pH}$ of elephant grass silages
}

\begin{abstract}
This work aimed to verify the efficiency of different additives on the chemical composition and fermentation parameters of elephant grass silage. The planting of elephant grass cv. Napier (Pennisetum purpureum Schum.) It was done in pits $25 \mathrm{~cm}$ deep with spacing lines of $80 \mathrm{~cm}$ after tillage. Elephant grass was harvested at 180 days of age and broken into fragments 0.5 to 2.0 $\mathrm{cm}$. The treatments were control (no additive); corn, $8 \%$ of the natural material, sodium chloride, $8 \%$ of the natural material, urea, $8 \%$ of the natural material, sugar, $8 \%$ of the natural material and cornmeal more sugar, $4 \%$ of the natural material of corn meal and $4 \%$ sugar. Analyses were carried out in dry matter (DM), crude protein (CP), neutral detergent fiber (NDF), acid detergent fiber (ADF), lignin (LGN), ether extract (EE) and ash (MM). Treatment with salt $(8 \%)$ had the highest rate bromatological, although the silage with the additive does not have appropriete protein levels. Urea at this
\end{abstract}


DEMINICIS, B.B. et al. Efeitos de diferentes aditivos sobre a composição bromatológica e pH de silagens de capim elefante. PUBVET, Londrina, V. 8, N. 13, Ed. 262, Art. 1739, Julho, 2014.

dose $(8 \%)$ prevents the silage by high-power alkaline. The high time to cut elephant grass (180 days) bromatological reduced the value of silage.

Keywords: Silage, Forage Conservation, Pennisetum purpureum

\section{INTRODUÇÃO}

As características climáticas de crescimento estacional das plantas forrageiras que ocorre na região sudeste brasileira influenciam na disponibilidade e regularidade no fornecimento de alimentos para os rebanhos de produção ao longo do ano, ocorrendo normalmente excesso durante a época das chuvas e escassez de forragem na pastagem durante a seca.

Perante a esta realidade, métodos de conservação de forragens desempenham importante papel reduzindo entraves na disponibilidade de alimentos, tornando assim, uma produção mais equilibrada durante o ano (JÚNIOR et al., 2007).

A necessidade de se utilizar alimentos de baixo custo, e melhorar níveis zootécnicos, traz a indispensabilidade de se aprofundar e melhorar técnicas já conhecidas de silagem (CRUZ et al., 2010).

A prática de ensilagem está relacionada com a conversão de carboidratos solúveis em ácido lático em condição de anaerobiose, promovendo a queda do $\mathrm{pH}$ da massa ensilada inibindo a atividade microbiana, consequentemente preservando suas características (JÚNIOR et al., 2007). Entre as variedades de gramíneas utilizadas para a produção de silagem, o capim-elefante (Pennisetum purpureum Schum.) tem se revelado superior a outras gramíneas tropicais por possuir bom valor bromatológico, alta produtividade por área durante o período das chuvas (outubro a março), baixo custo de produção, além do fato de que muitas propriedades já possuem pastagens inseridas de capim- (TOSI et al., 1989; RESENDE et al., 2008).

Entretanto, no momento ideal de corte do capim-elefante (60-70 dias), ocorre a presença de alto teor de umidade, além de baixo teor de carboidratos solúveis, prejudicando o processo fermentativo e o rápido declínio do pH. Este 
DEMINICIS, B.B. et al. Efeitos de diferentes aditivos sobre a composição bromatológica e pH de silagens de capim elefante. PUBVET, Londrina, V. 8, N. 13, Ed. 262, Art. 1739, Julho, 2014.

fato permite fermentações secundárias indesejáveis reduzindo a qualidade da silagem (MCDONALD, 1981).

O uso de aditivos absorventes ou sequestrantes de umidade é uma das técnicas mais indicadas para o controle da qualidade das silagens. Alguns aditivos absorventes, além de favorecerem o aumento do teor de matéria seca, proporcionam incremento do valor nutritivo (ANDRADE et al., 2010). Vários estudos têm sido realizados no intuito de avaliar tratamentos que alteram o processo fermentativo das silagens de capim-elefante. Tais trabalhos envolveram adições de fontes de carboidratos, seqüestradores de umidade, emurchecimento prévio do capim, adição de inóculos bacterianos e de substâncias nitrogenadas (ANDRADE e MELLOTI, 2004).

Visto isso, este trabalho propõe avaliar os efeitos de diferentes aditivos (fubá, uréia, cloreto de sódio, fubá com açúcar, e açúcar) na perspectiva de elevar os níveis de matéria seca e carboidratos solúveis na massa ensilada tornando uma fermentação mais eficiente, além da elevação do potencial nutricional da silagem de capim-elefante. Embora a real intenção de utilizar os referidos aditivos é avaliar o efeito sobre o pH e a composição bromatológica, pretende-se com fubá principalmente elevar os teores de carboidratos solúveis. A uréia foi utilizada no intuito de suplementar proteína normalmente deficiente em capineiras e silagens. O cloreto de sódio foi utilizado na intenção de elevar os teores de matéria seca. Açúcar e fubá com açúcar foram utilizados na perspectiva de se elevar os teores de carboidratos solúveis e aumentar os teores de matéria seca.

\section{MATERIAIS E MÉTODOS}

O experimento foi conduzido no Núcleo de Pesquisa em Zootecnia da Universidade Estadual Norte Fluminense (UENF), em Campos dos Goytacazes, RJ e no Laboratório de bromatologia do Departamento de Zootecnia da Universidade Federal do Espírito santo (UFES), entre janeiro e novembro de 2011. O padrão climático da região Norte Fluminense é descrito como Aw, 
DEMINICIS, B.B. et al. Efeitos de diferentes aditivos sobre a composição bromatológica e pH de silagens de capim elefante. PUBVET, Londrina, V. 8, N. 13, Ed. 262, Art. 1739, Julho, 2014.

tropical quente úmido, com período seco no inverno e chuvoso no verão, segundo classificação de Köppen. O plantio do capim-elefante cv. Napier (Pennisetum purpureum Schum.) foi feito em covas de $25 \mathrm{~cm}$ de profundidade com espaçamento entre linhas de $80 \mathrm{~cm}$, após o preparo do solo. 0 capimelefante foi colhido aos 180 dias de idade e triturado em partículas de 0,5 a $2,0 \mathrm{~cm}$.

Os tratamentos consistiram em controle (sem aditivo); fubá de milho, à $8 \%$ da matéria natural; cloreto de sódio, à $8 \%$ da matéria natural; uréia, à $8 \%$ da matéria natural, açúcar cristal, à $8 \%$ na matéria natural e fubá de milho mais açúcar cristal, à $4 \%$ da matéria natural de fubá e $4 \%$ de açúcar cristal. Os aditivos foram adicionados na massa forrageira, de forma homogênea. $O$ material foi ensilado em microsilos laboratoriais tipo "Pronaf", com capacidade de aproximadamente de $5,5 \mathrm{~kg}(40 \mathrm{~cm}$ de comprimento e $100 \mathrm{~cm}$ de diâmetro) por tratamento, totalizando 24 microsilos experimentais (6 aditivos com 4 repetições). Os microsilos foram mantidos em local à sombra, em temperatura ambiente. Amostras foram tomadas aos 35 dias após a ensilagem, para verificação da influência dos aditivos na fermentação das silagens. Após a abertura dos silos, procedeu-se a determinação do $\mathrm{pH}$, em água, de cada silagem conforme metodologia descrita por Silva e Queiroz (2002). Posteriormente, amostras foram coletadas em triplicata, identificadas e congeladas para posteriores análises laboratoriais. No laboratório de nutrição do Departamento de Zootecnia da UFES, foram realizadas análises de matéria seca (MS), proteína bruta ( $P B)$, fibra em detergente neutro, extrato etéreo (EE) e matéria mineral (MM) segundo metodologias descritas por silva e Queiroz (2002).

Os dados foram analisados por meio de análise de variância e as médias foram comparadas pelo teste Tukey em nível de $5 \%$ de significância utilizando a ferramenta estatística SISVAR (FERREIRA, 2000). 
DEMINICIS, B.B. et al. Efeitos de diferentes aditivos sobre a composição bromatológica e pH de silagens de capim elefante. PUBVET, Londrina, V. 8, N. 13, Ed. 262, Art. 1739, Julho, 2014.

\section{RESULTADOS E DISCUSSÃO}

Os resultados dos efeitos dos aditivos sobre o pH e composição bromatológica de silagem de capim elefante estão apresentados na Tabela 1.

Tabela 1. pH e composição bromatológica da silagem de capim elefante com diferentes aditivos.

\begin{tabular}{ccccccccc}
\hline Trat. & pH & MS\% & PB\% & FDN\% & FDA\% & LIG\% & M.M.\% & EE\% \\
\hline 1 & $3,42 \mathrm{c}$ & $35,39 \mathrm{c}$ & $9,60 \mathrm{~b}$ & $79,86 \mathrm{ab}$ & $59,22 \mathrm{ab}$ & $8,42 \mathrm{bc}$ & $4,88 \mathrm{c}$ & $1,28 \mathrm{a}$ \\
2 & $4,10 \mathrm{~b}$ & $43,92 \mathrm{ab}$ & $7,30 \mathrm{c}$ & $80,51 \mathrm{a}$ & $58,27 \mathrm{ab}$ & $7,52 \mathrm{c}$ & $5,97 \mathrm{ab}$ & $2,04 \mathrm{a}$ \\
3 & $3,25 \mathrm{c}$ & $48,14 \mathrm{a}$ & $8,80 \mathrm{~b}$ & $82,44 \mathrm{a}$ & $64,15 \mathrm{a}$ & $8,33 \mathrm{bc}$ & $6,54 \mathrm{ab}$ & $2,08 \mathrm{a}$ \\
4 & $3,85 \mathrm{~b}$ & $49,96 \mathrm{a}$ & $3,60 \mathrm{~d}$ & $72,56 \mathrm{c}$ & $54,70 \mathrm{c}$ & $9,11 \mathrm{ab}$ & $11,14 \mathrm{a}$ & $1,50 \mathrm{a}$ \\
5 & $8,85 \mathrm{a}$ & $40,74 \mathrm{ab}$ & $20,70 \mathrm{a}$ & $80,08 \mathrm{ab}$ & $63,45 \mathrm{a}$ & $9,03 \mathrm{ab}$ & $5,60 \mathrm{c}$ & $1,86 \mathrm{a}$ \\
6 & $4,12 \mathrm{~b}$ & $44,07 \mathrm{ab}$ & $3,50 \mathrm{~d}$ & $84,71 \mathrm{a}$ & $61,35 \mathrm{ab}$ & $10,10 \mathrm{a}$ & $6,89 \mathrm{ab}$ & $1,23 \mathrm{a}$ \\
\hline CV\% & 3,42 & 12,62 & 5,73 & 4,18 & 5,82 & 7,07 & 35,44 & 27,36
\end{tabular}

* Medias seguidas pela mesma letra minúsculas nas linhas não diferem entre si, pelo teste de Tukey, a 5\% de probabilidade. 1 = Açúcar 8\%; 2 = Fubá 8\%, 3 = Açúcar 4\% + Fubá 4\%; 4 = $\mathrm{NaCl} ; 5=$ Uréia e $6=$ Controle.

Observa-se que houve diferença significativa no efeito dos aditivos sobre o teor de matéria-seca das silagens. Todos os tratamentos atingiram o teor mínimo de $26 \%$ de matéria seca necessários para uma silagem de boa qualidade segundo Haigh (1990). Porém, apenas o tratamento com açúcar se aproximou do valor aceitável máximo de 35\% de matéria seca necessários para uma eficiente compactação, evitando eventual desenvolvimento de mofo (OLIVEIRA, 1997).

Itavo et al., (2010), encontraram valores de MS para capim elefante com $39,42 \%$ na matéria natural, $39,49 \%$ no fubá $(8 \%), 52,39 \%$ no sal $(8 \%)$, $44,62 \%$ na uréia (8\%). Estas variações que podem ser provavelmente explicadas pela diferença de metodologias utilizadas na confecção dos silos. Desta forma, os resultados verificados no presente trabalho corroboram com Itavo et al., (2010) que mostram como maiores teores obtidos por tratamentos 
DEMINICIS, B.B. et al. Efeitos de diferentes aditivos sobre a composição bromatológica e pH de silagens de capim elefante. PUBVET, Londrina, V. 8, N. 13, Ed. 262, Art. 1739, Julho, 2014.

que utilizaram cloreto de sódio ( $8 \%$ ) quando comparados com outros aditivos. Provavelmente este fato pode ser explicado pelo potencial natural higroscópico da substância. As médias dos teores de MS podem ser consideradas elevadas para silagens de capins (VILELA, 1998), provavelmente devido à idade de corte do capim-elefante (180 dias).

Quanto a avaliação do $\mathrm{pH}$, também houve diferença significativa entre os tratamentos. Com exceção do tratamento com uréia à $8 \%$, todos os tratamentos atingiram os níveis adequados de $\mathrm{pH}(3,8$ a 4,0$)$ propostos por Rotz e Muck (1994), garantindo a estabilidade da silagem. Silagens tratadas com uréia e com eficiente transformação da mesma em amônia resultam em silagens com pH superior ao das não tratadas. $\mathrm{O}$ aumento do $\mathrm{pH}$ em silagens amonizadas é atribuído ao fato de que a amônia possui alta capacidade tamponante, pois evita que a produção de ácido provoque queda acentuada do mesmo (NEIVA et al., 1998). Entretanto, o valor do pH final não pode ser tomado isoladamente como um critério definitivo para avaliação das fermentações, pois a inibição das fermentações secundárias depende mais da velocidade de redução da concentração iônica e da umidade do meio do que o pH final do produto (WOOLFORD, 1984). A utilização de uréia na forrageira a ser ensilada é justificada pelo atributo de elevar o teor de proteína da silagem, evidenciado na Tabela 1, além da transformação de uréia em amônia (NH3), que reage com água de modo a formar hidróxido de amônia, com elevação de $\mathrm{pH}$ e atuação sobre o metabolismo de microorganismos indesejáveis, principalmente leveduras. A utilização de uréia em silagens pode reduzir as perdas no processo de ensilagem e corrigir o déficit protéico. (ITAVO et al., 2010).

Contudo, a inclusão de uréia afetou claramente o processo fermentativo, o que também foi observado por Yunus et al., (2000) e Vilela e Wilkinoson (1987). Sua ação alcalinizante, impede a redução do $\mathrm{pH}$ o que favorece o desenvolvimento das bactérias indesejáveis (ANDRADE e MELLOTI 2004). O baixo teor de $\mathrm{PB}$ observado na silagem controle pode ser atribuído à perda de compostos nitrogenados solúveis no efluente (SOUZA et al., 2003). Ferreira et 
DEMINICIS, B.B. et al. Efeitos de diferentes aditivos sobre a composição bromatológica e pH de silagens de capim elefante. PUBVET, Londrina, V. 8, N. 13, Ed. 262, Art. 1739, Julho, 2014.

al., (2004) encontraram para silagem de capim-elefante 3,3\% de PB, 2,2\% de $\mathrm{EE}, 7,1 \%$ de lignina, $46,6 \%$ de FDA, valores relativamente aproximados, mas que destoam dos resultados observados no presente estudo provavelmente pelo menor tempo de corte (80 dias) (CRUZ et al., 2010). Analisando PB em silagens de capim elefante com diferentes aditivos, Itavo et al., (2010) encontraram 8,05\% para o tratamento controle, 8,17\% para Fubá ( $8 \%$ da matéria natural), $7,24 \%$ para $\mathrm{NaCl}$ ( $8 \%$ da matéria natural), 23\% para Uréia ( $8 \%$ da matéria natural) com 180 dias de idade de corte.

Em relação aos teores de FDN também foram observadas diferenças estatísticas entre os tratamentos. As porcentagens de FDN observadas nas silagens estão acima do recomendado por Soest (1994), para não inibir consumo e digestibilidade da MS. O autor relata ainda que o aumento de valores de FDN esteja correlacionado negativamente com consumo do alimento, no qual o limite estaria próximo a $55 \%$ a $60 \%$.

Almeida et al., (2006), analisando diferentes porcentagens de açúcar em silagem de capim elefante relataram que os teores de FDA só sofreram diferenças significativas a partir da adição de $2 \%$ de açúcar. Estes teores de açúcar, segundo Andrade (1995), sugerem que as silagens podem apresentar alto consumo pelos animais devido aos baixos teores de FDA, que apesar disso podem não ser digeríveis pelas bactérias ruminais, pois quanto maior forem estes teores, menor será o consumo de matéria seca, o que levará a um menor consumo do alimento pelo animal. Neste mesmo trabalho, o autor observou que os níveis de lignina sofreram redução de acordo que se aumentavam as doses de açúcar, situação favorável, uma vez que estaria proporcionando um maior consumo de alimento. Reduções significativas de FDA e lignina utilizando açúcar foram evidenciadas no presente estudo, apesar de os valores permanecerem altos provavelmente pela alta idade de corte (180 dias).

Rezende et al., (2008) encontraram 69,79\% e 48,82\% para FDN e FDA respectivamente, valores que são menores do presente estudo provavelmente pelo menor tempo de corte (70 dias). Souza et al., (2003) e Bernardino et al., 
DEMINICIS, B.B. et al. Efeitos de diferentes aditivos sobre a composição bromatológica e pH de silagens de capim elefante. PUBVET, Londrina, V. 8, N. 13, Ed. 262, Art. 1739, Julho, 2014.

(2005) encontraram $6,73 \%$ e $8,4 \%$ de lignina em silagem de capim elefante respectivamente. $O$ elevado teor de lignina na composição dos tratamentos provavelmente contribui para redução da digestibilidade (SOUZA et al., 2001). Segundo Van Soest (1994), a lignina é o fator mais significante que limita a disponibilidade da parede celular da planta aos animais herbívoros nos sistemas de digestão anaeróbios. Faria et al., (2007) observaram o teor de $11,32 \%$ de lignina em silagem de capim elefante, valor muito semelhante ao encontrado no presente estudo. Vilela et al (2008) avaliando as características bromatológicas de silagens de milho produzidas com milho em diversos estágios de maturação verificaram que a porcentagem de lignina variou de 3,6 a 5,6\%, como resultado da tendência de lignificação com o avanço do estádio de maturação.

Os resultados observados no presente estudo mostraram que não houve diferença significativa dos tratamentos sobre as porcentagens de extrato etéreo das silagens, sendo verificada média de 1,65\% de E.E. Ferreira et al., (2004) encontraram 2,2\% de EE em silagem de capim elefante cv. Napier (Pennisetum purpureum Schum), valor muito próximo do encontrado no presente estudo. Junior et al., observaram 2,81\% de EE em silagem de capim elefante paraíso (Pennisetum hybridum $\mathrm{cv}$. paraiso) onde esta ligeira diferença possivelmente pode ser explicada pela diferença de variedade do capim. Todos os tratamentos do presente estudo se apresentaram abaixo do limite máximo de $5 \%$ de $\mathrm{EE}$, a partir do qual há comprometimento do consumo da matéria seca pelo animal (PALMQUIST, 1994).

Possenti et al., (2005) avaliando parâmetros bromatológicos e fermentativos das silagens de milho e girassol observaram teores de extrato etéreo de $10, \%$ e $3,2 \%$, respectivamente.

Ferrari e Lavezzo (2001) avaliando a silagem de capim elefante cv. Taiwan A-146, submetida ao emurchecido ao sol por 8 horas, sem emurchecimento, com farelo de mandioca $(2 \%)$, com farelo de mandioca (4\%), com farelo de mandioca ( $8 \%)$ e com farelo de mandioca (12\%), verificaram que a média de 5,86\% de MM para silagens e que não houve 
DEMINICIS, B.B. et al. Efeitos de diferentes aditivos sobre a composição bromatológica e pH de silagens de capim elefante. PUBVET, Londrina, V. 8, N. 13, Ed. 262, Art. 1739, Julho, 2014.

diferença significativa entre os tratamentos. Cruz et al., (2010) avaliando a composição bromatológica das silagens de capim elefante contendo diferentes níveis de inclusão $(0 ; 10 ; 20$ e 30\%) de casca de maracujá desidratada (CMD) na matéria natural do capim-elefante, observaram teores médios de 9,8\% de matéria mineral. Rodrigues Neto et al., (2001) em um trabalho estudando a qualidade e o valor nutritivo de silagens do subproduto da pupunha, produzidas com adição de açúcar; de polpa cítrica e milho moído, verificaram o menor teor médios de matéria mineral de $6,7 \%$. O cloreto de sódio ( $8 \%)$, no presente trabalho, obteve o maior valor de matéria mineral (MM) entre os aditivos $(11,4 \%)$, fato que se explica pela sua origem mineral. Em um trabalho com silagem de capim elefante, Junior et al., (2007) encontraram o teor de $6,9 \%$ de matéria mineral em silagem de capim-elefante paraíso (Pennisetum hybridum), valor muito próximo ao encontrado neste trabalho $(6,8 \%)$ para o tratamento controle.

\section{CONCLUSÃO}

A uréia nesta dosagem ( $8 \%$ ) inviabiliza a silagem pela acentuada alcalinização. O tempo de corte do capim (180 dias) prejudicou o valor bromatológico da silagem. $\mathrm{O} \mathrm{NaCl}(8 \%)$ apresentou adequado resultado para $\mathrm{pH}$, alta capacidade de elevar o teor de matéria seca, menores concentrações de FDN e FDA, e alto teor de matéria mineral embora com níveis reduzidos de proteína bruta. O açúcar (8\%) apresentou adequado índice de MS para não desenvolvimento de mofo e alta capacidade de elevar proteína bruta. O fubá apresentou maior capacidade de reduzir o teor de lignina.

\section{REFERÊNCIAS}

ANDRADE, I.V.O; PIRES, A.J.V; CARVALHO, G.G.P; VELOSO, C.M; BONOMO, P. Perdas, características fermentativas e valor nutritivo da silagem de capim-elefante contendo subprodutos agrícolas. Revista Brasileira de Zootecnia, v.39, n.12, 2010. 
ANDRADE, J.B. Efeito da adição de rolão de milho, farelo de trigo e sacharina naensilagem de capim-elefante (Pennisetum purpureum Schum.). Botucatu, SP: UNESP-FMVZ, 1995. 190p. Tese (Doutorado em Nutrição e Produção Animal) Faculdade De Medicina Veterinária e Zootecnia. Universidade Estadual Paulista, 1995.

ANDRADE, S.J.T; MELOTTI, L. Efeito de alguns tratamentos sobre a qualidade da silagem de capim-elefante cultivar Napier. Brazilian Journ al of Veterinary Research and Animal Science, Pirassununga, v.41, p.409-415, 2004.

ALMEIDA, J.C.C; MUNHOZ, N.G.A; PERALI, C. Avaliação bromatológica da silagem de capimelefante (Pennisetum purpureum cv. napier schum.) com adição de diferentes doses de açúcar. In: ZOOTEC, Anais... Recife: UFRPE, 2006.

CRUZ, B.C.C; CRUZ, C.L.S; PIRES, A.J.V; ROCHA, J.B; SANTOS S; BASTOS M.P.V. Composição bromatológica da silagem de capim-elefante com diferentes proporções de casca desidratada de maracujá. Revista Brasileira de Zootecnia, Recife, v.5, n.3, p.434-440, 2010.

FARIA, D.J.G; GARCIA, R; PEREIRA, O.G; FONSECA, D.M; MELLO, R; RIGUEIRA, J.P,S; . Composição químico-bromatológica da silagem de capim-elefante com níveis de casca de café. Revista Brasileira de Zootecnia. v.36, n.2, p.301-308, 2007.

FERRARI, JR, E.; LAVEZZO, W. Qualidade da Silagem de Capim-Elefante (Pennisetum purpureum Schum.). Emurchecido ou Acrescido de Farelo de Mandioca. Revista Brasileira de Zootecnia. 30(5):1424-1431, 200.

FERREIRA, A. C. H; NEIVA, J. N. M; RODRIGUEZ, N. M; LÔBO, R. N. B; VASCONCELOS, A. R. Valor Nutritivo das Silagens de Capim-Elefante com Diferentes Níveis de Subprodutos da Indústria do Suco de Caju. Revista Brasileira de Zootecnia, v.33, n.6, p.1380-1385, 2004.

FERREIRA, D.F. Sistema de análises de variância para dados balanceados. Lavras: UFLA, 2000. (SISVAR 4. 1. pacote computacional).

HAIGH, P.M. Effect of herbage water-soluble carbohydrate content and weather conditions at ensilage on the fermentation of grass silages made on commercial farms. Grass and Forage Sciencie, v.81, p.263-271, 1990.

ITAVO, L.C.V; ITAVO, C.C.B.F; MORAIS, M.G.; DIAS, A.M; COELHO, E.M.; JELLER, H; SOUZA, A.D.V. Composição química e parâmetros fermentativos de silagens de capim-elefante e cana-de-açúcar tratadas com aditivos. Revista Brasileira de Saúde e Produção Animal, v.11, p.606-617, 2010.

JÚNIOR, E.F.; PAULINO V.T.; POSSENTIL, R.A; LUCENAS T.L. Aditivos em Silagem de Capim Elefante Paraíso. Revista Brasileira de Zootecnia, São Paulo, v.58, n.222, p.193, 2007.

MCDONALD, P. The biochemistry of silage. New York: Jonh Wiley \& Sons, 1981. 226p.

NEIVA, J.N.; GARCIA, R.; VALADARES, F.S.C.; PIRES, A.J.V.; PEREIRA, O.G.; SILVA, H.A. (1998) Características químicas da silagem e do rolão de milho amonizados. Revista Brasileira de Zootecnia, v.27, n.3, p.46-645. 1998.

OLIVEIRA, C.L.M. Avaliação nutricional de silagens de híbridos de Sorghum bicolor x Sorghum sudanese. Belo Horizonte: Escola de Veterinária da UFMG, 1997. p.63. Dissertação (Mestrado em Zootecnia), 1997.

POSSENTI, R.A.; FERRARI JR, E.; BUENO, M.S.; BIANCHINI, D.; LEINZ, F.F.; RODRIGUES, C.F. Parâmetros bromatológicos e fermentativos das silagens de milho e girassol. Ciência Rural, v.35, n.5, p.1185-1189, 2005. 
REZENDE, A.V.; JÚNIOR, A.L.G.; VALERIANO, A.R.; CASALI A.O.; MEDEIROS, L.T.; RODRIGUES, R. Uso de diferentes aditivos na ensilagem de capim-elefante. Ciência e Agrotecnologia, v.32, n.1, p,.281-287, 2008.

ROTZ, C.A.,MUCK, R.E. 1994. Changes in forage quality during harvest and torage. In: National Conference on Forage Quality, Evaluation, and Utilization Held at TheUniversity of Nebraska, Lincoln, p.828-868, 1994.

SOEST, P.J. Van. Nutritional ecology of the ruminant. 2. ed. Ithaca: Cornell University, 1994. $476 \mathrm{p}$.

SOUZA, A.L.; BERNARDINO F.S; GARCIA, R.; PEREIRA, O.G; ROCHA, F.C.; PIRES, A. J. V. Valor nutritivo de silagem de capim-elefante (Pennisetum purpureum Schum.) com diferentes níveis de casca de café. Revista Brasileira de Zootecnia v.32, n.4, p.828-833, 2003.

TOSI, H.; BONASSI, I.A; ITURRINO, R.P.S. Avaliação química e microbiológica da silagem de capim elefante, cultivar Taiwan A- 148, preparada com bagaço de cana-de- açúcar. Pesquisa Agropecuária Brasileira, v.24, n. 11, p. 1313-1317, 1989.

VILELA, D. Aditivos para silagem de plantas de clima tropical. In: Reunião Da Sociedade Brasileira De Zootecnia, 34., 1998, Botucatu. Anais... Botucatu: SBZ, 1998. p.73-108.

VILELA, D., WILKINSON, J.M. Efeito do emurchecimento e da adição de uréia sobre a fermentação e digestibilidade 'in vitro' do capim-elefante (Pennisetum purpureum) ensilado. Revista da Sociedade Brasileira de Zootecnia., v. 16, n. 6, p. 550-562, 1987.

VILELA, H.H.; REZENDE, A.V.; VIEIRA, P.F.; ANDRADE, G.A.; EVANGELISTA, A.R.; ALMEIDA, G.B.S. Valor nutritivo de silagens de milho colhido em diversos estádios de maturação. Revista Brasileira de Zootecnia, v.37, n.7, p.1192-1199, 2008.

WOOLFORD, M.K. The silage fermentation. New York: M. Dekker, 1984. 322 p, 1984.

YUNUS, M.; OHBA, N.; SHIMOJO, M. Effects of adding urea and molasses on napiergrasss silage quality. Asian Australasian Journal of Animal Sciences., v.13, n. 11, p. 15421547, 2000. 